Joost Wauters

Ingrid Baar

Philippe Meersseman

Wouter Meersseman

Karolien Dams

Rudi De Paep

Katrien Lagrou

Alexander Wilmer

Philippe Jorens

Greet Hermans

\title{
Invasive pulmonary aspergillosis is a frequent
complication of critically ill H1N1 patients: \\ Invasive pulmonary aspergillosis is a frequent
complication of critically ill H1N1 patients: a retrospective study
}

\begin{abstract}
Purpose: Despite their controversial role, corticosteroids (CS) are frequently administered to patients with $\mathrm{H} 1 \mathrm{~N} 1$ virus infection with severe respiratory failure secondary to viral pneumonia. We hypothesized that invasive pulmonary aspergillosis (IPA) is a frequent complication in critically ill patients with $\mathrm{H} 1 \mathrm{~N} 1$ virus infection and that CS may contribute to this complication. Methods: We retrospectively selected all adult patients with confirmed H1N1 virus infection admitted to the intensive care unit (ICU) of two tertiary care hospitals from September 2009 to March 2011. Differences in baseline factors, risk factors, and outcome parameters were studied between patients with and without IPA. Results: Of 40 critically ill patients with confirmed H1N1, 9

$p=0.002$ ). IPA patients also received significantly higher doses of $\mathrm{CS}$ before ICU admission [hydrocortisone equivalent $800(360-2,635)$ versus $0(0-0) \mathrm{mg}, p=0.005]$. On multivariate analysis, use of CS before ICU admission was independently associated with IPA [odds ratio (OR) 14.4 (2.0-101.6), $p=0.007]$. Conclusions: IPA was diagnosed in $23 \%$ of critically ill patients with H1N1 virus infection after a median of 3 days after ICU admission. Our data suggest that use of CS 7 days before ICU admission is an independent risk factor for fungal superinfection. These findings may have consequences for clinical practice as they point out the need for increased awareness of IPA, especially in those critically ill H1N1 patients already receiving CS.
\end{abstract} (23\%) developed IPA 3 days after ICU admission. Five patients had proven and four had probable IPA. Significantly more IPA patients received CS within 7 days before ICU admission (78 versus $23 \%$,
Keywords H1N1 · Fungal · Corticosteroid $\cdot$ ICU $\cdot$ Aspergillosis

\section{K. Lagrou} \\ Laboratory Medicine, University Hospitals \\ Leuven, Leuven, Belgium \\ I. Baar - K. Dams - R. De Paep - P. Jorens \\ Intensive Care Unit, Antwerp University
}

\section{Introduction}

Since June 2009, infection with influenza A (H1N1) virus has reached pandemic proportions. A minority of patients with H1N1 virus infection (0.3-13\%) needed hospitalization, and $10-30 \%$ of these developed rapidly progressive pneumonia. The ensuing profound inflammatory response caused the most severe form of acute lung injury, called acute respiratory distress syndrome (ARDS), either isolated or as part of a multiple organ dysfunction syndrome (MODS) [1]. ARDS due to this infection was associated with a high mortality rate $(14-41 \%)[1,2]$. Controversy exists regarding use of anti-inflammatory agents such as corticosteroids (CS) for ARDS. While an initial meta-analysis concluded that a definitive role of CS in ARDS was not established, a more 
recent one reported improved mortality as well as length of stay and less organ dysfunction with early, low- to moderate-dose CS in some subgroups of ARDS patients $[3,4]$.

Despite their controversial role, CS have been administered to 18-69\% of patients with ARDS secondary to H1N1 virus infection [5-7]. However, several recent studies reported possible harmful effects of CS in severe pneumonia due to H1N1 virus infection. Two groups of investigators found that CS administration (very early) in the course of H1N1-related ARDS was associated with significantly higher ICU and hospital mortality [8, 9]. Martin-Loeches et al. [10] also reported in a worldwide population that early use of CS did not result in better outcome and was associated with increased risk for superinfection.

Remarkably, use of CS is associated with increased incidence of invasive aspergillosis in chronic obstructive pulmonary disease (COPD) patients with severe respiratory insufficiency [11]. Invasive aspergillosis is also described as a dreaded complication with high mortality in critically ill patients without malignancy or neutropenia $[11,12]$. Recent clinical reports suggest that CS therapy may be associated with increased ICU-acquired pneumonia and possibly favor fungal superinfection in patients with H1N1 virus infection [8, 13]. However, in these studies, including 465 patients, only $2 \%$ of critically ill patients with $\mathrm{H} 1 \mathrm{~N} 1$ virus infection were found to develop invasive pulmonary aspergillosis (IPA). In addition, case reports of IPA as a fungal superinfection in critically patients with $\mathrm{H} 1 \mathrm{~N} 1$ virus infection have been described recently [13-18].

In the present observational study, we hypothesize that IPA is a much more frequent complication in critically ill H1N1 patients and that use of CS may contribute to this superinfection.

\section{Materials and methods}

Study population

We retrospectively reviewed the medical records of all patients who were admitted to the adult intensive care units of two tertiary hospitals [University Hospitals Leuven (UZL), Leuven, Belgium and Antwerp University Hospital (UZA), Edegem, Belgium] from September 2009 to March 2011 in whom H1N1 virus infection was diagnosed during or 1 week prior to ICU stay. The medical ICU of UZL has 17 beds, whereas the mixed ICU of UZA has 45 beds. Patients $<18$ years old were excluded. Diagnosis of H1N1 virus infection was based on a positive result from a probe-based reverse-transcriptase polymerase chain reaction (RT$\mathrm{PCR})$ test for $\mathrm{H} 1 \mathrm{~N} 1$ from a nasopharyngeal swab or bronchoalveolar lavage (BAL). This observational retrospective study without any specific intervention was reviewed and approved by both hospitals' Institutional Review Boards, and all data were processed anonymously. Informed consent was waived by both ethics committees.

\section{Definitions}

For the remainder of the manuscript, we abbreviate "patients with H1N1 virus infection" as "H1N1 patients" for the sake of simplicity. Invasive pulmonary aspergillosis was diagnosed based on the revised EORTC/MSG consensus group (European Organization for Research and Treatment of Cancer/Invasive Fungal Infections Cooperative Group and the National Institute of Allergy and Infectious Diseases Mycoses Study Group) guidelines [19]. Patients had proven IPA if there was microscopic evidence of dichotomous branching hyphae with positive culture for Aspergillus spp. from endobronchial biopsy (not BAL), irrespective of host factors or clinical features. Probable IPA required a host factor, clinical features, and mycological evidence of aspergillosis. Since host factors in the revised EORTC definitions are basically intended for immunocompromised hematological patients, we defined broader risk factors, based on "modified EORTC criteria," according to our previous prospective study on the value of BAL for diagnosis of Aspergillus in ICU patients [20]. Mycological evidence was based on microscopy or culture of Aspergillus spp. cultured from a BAL specimen or a galactomannan (GM) optical index $>0.5$ from a BAL or serum sample. Sandwich enzymelinked immunosorbent assay (ELISA) for GM detection (Platelia Aspergillus; Bio-Rad Laboratories, Marnes-laCoquette, France) was performed according to the instructions of the manufacturer $[20,21]$. Lower tract respiratory samples were inoculated onto a Sabouraud agar $\left(2\right.$ days at $37{ }^{\circ} \mathrm{C}$ and another 19 days at $30{ }^{\circ} \mathrm{C}$ ) for fungal isolation. Aspergillus species were identified by their culture characteristics and morphologies. During the study period, routine baseline monitoring was performed in the ICU and in all high-risk wards taking care of oncology, hematology, and transplant patients. This monitoring was performed at least once a year [22]. Severity of illness was assessed based on the Acute Physiology and Chronic Evaluation Score (APACHE) II score and the Sequential Organ Failure Assessment (SOFA) score $24 \mathrm{~h}$ after admission. Patients were considered immunosuppressed at baseline in case of underlying malignant hematological disease, solid-organ transplant recipient, or any other illness necessitating immunosuppressive therapy. Neutropenia was defined as neutrophils $<500 / \mathrm{mm}^{3}$ for $>10$ days. In both centers, the doses and frequency of all drugs administered in the month before and during admission to the ICU were 
recorded in the medical records and the patient data management system (PDMS, Metavision; iMDsoft, Boston, USA). Day of ICU admission was called day 0. All $\mathrm{CS}$ doses are expressed in mg hydrocortisone equivalent. Outcome measures included ICU or hospital survival and length of stay, days of organ support [mechanical ventilation, inhaled nitric oxide (NO) or high-frequency rescue ventilation, extracorporeal membrane oxygenation (ECMO), vasopressor, renal replacement therapy], and ICU complications (bacteremia, ventilator-associated pneumonia). In both centers, CS were started on ICU in patients with refractory shock and/or late ARDS, according to the treating physician's judgement.

\section{Statistical analysis}

Data were analyzed with SPSS (SPSS Inc., Chicago, USA). Data are reported as percentage for categorical variables and as mean \pm standard deviation (SD) or median with interquartile range (IQR), as appropriate, for continuous variables. In univariate analysis, categorical variables were compared by Fisher's exact test and continuous variables were compared by $t$ test or MannWhitney $U$ test as appropriate. Multivariate analysis was done by backward and forward stepwise logistic regression including known risk factors for IPA and baseline factors significantly different between IPA and non-IPA patients. All tests of significance were two-tailed, and $p$ value of 0.05 was considered significant.

\section{Results}

Patient characteristics

Between September 2009 and March 2011, we included 40 adult critically ill patients with confirmed H1N1 infection: $24 / 40$ (60 \%) in UZL and 16/40 (40 \%) in UZA (Table 1). The total number of admissions during the study period was 5,260. Eighteen of $40(45 \%)$ patients had H1N1 in the 2009 season, while 22/40 (55\%) had H1N1 in the 2010 season. H1N1 infection was diagnosed during ICU stay in 31/40 (78 \%) patients, while H1N1 was diagnosed shortly before ICU admission in 9/40 $(22 \%)$ patients. The patients had mean age of $49 \pm 14$ years, and 23/40 (58 \%) were men. On admission, the mean APACHE II score was $23 \pm 8$ and the median SOFA score was 11 (5-13), reflecting a high severity of illness and a high incidence of MODS. Thirtyfive patients $(88 \%)$ were mechanically ventilated for median duration of $11(5-13)$ days. Seven patients (18\%) received CS during ICU stay as rescue therapy for "late ARDS." Twenty-one (52\%) patients needed rescue therapy with NO ventilation for refractory hypoxemia, and $11(28 \%)$ of these patients received ECMO. Other baseline factors are described in Table 1.

\section{Invasive pulmonary aspergillosis (IPA)}

Twenty-three percent (9/40) of these critically ill H1N1 patients developed IPA as early as 3 days after ICU admission, being 2 days after H1N1 diagnosis (Table 2). Figure 1 reflects the distribution of H1N1 cases in ICU over time and the proportion of those patients who were diagnosed with IPA. In all 40 included H1N1 patients, at least one lower tract respiratory sample was inoculated onto a Sabouraud agar for fungal isolation. Aspergillus fumigatus was isolated in lower respiratory tract sample cultures of 8/9 cases of IPA. In one IPA patient, microbiological data were limited to GM detection in BAL and serum, in combination with new bilateral infiltrates on chest X-ray and macroscopic white pseudomembranous lesions on bronchoscopy. Unfortunately, the biopsy specimens of these bronchial lesions were lost for microscopic or microbiological processing. Five patients had "proven" disease. "Probable" infection was diagnosed in the other 4/9 patients. All but one of the latter four patients had positive Aspergillus BAL cultures, and all four patients had a positive BAL GM (Table 2). All patients who received amoxicillin-clavulanate or piperacillin-tazobactam in the 5 days before a positive GM detection had multiple confirmatory positive GM samples clearly separated in time ( $\geq 4$ days later) from the latest administration of these antibiotics $(n=3)$ or had "proven" fungal infection $(n=1)$. All IPA patients received voriconazole for $43 \pm 19$ days. At the time of the ICU admissions, there were no works in progress in either of the two hospitals in the vicinity of the patients' wards. In both centers, extensive environmental fungal sampling is performed regularly in the ICU and the hospital wards. During both H1N1 seasons only very few environmental fungal isolates could be detected, and there was no increase compared with previous years. Four of nine IPA patients were transferred from a referral hospital, and no data regarding environmental fungal sampling in these referral hospitals were available. Table 1 presents the differences in baseline characteristics, risk factors, and outcome parameters between IPA and non-IPA patients. IPA patients were mostly men. No patients were known with liver cirrhosis or had neutropenia during their ICU stay. There was no difference in the number of IPA versus non-IPA patients developing ventilator-associated pneumonia, but IPA patients had more bacteremia during ICU admission. Importantly, ICU stay [26 (13-69) versus 15 (7-25) days, $p=0.03]$ and hospital length of stay [58 (26-65) versus 23 (12-36) days, $p=0.02$ ] were significantly higher in IPA versus non-IPA patients. ICU and hospital mortality tended to be higher in IPA patients, without reaching statistical significance. 
Table 1 Overview of the characteristics of all patients

\begin{tabular}{|c|c|c|c|c|}
\hline & All patients $(n=40)$ & IPA $(n=9)$ & No IPA $(n=31)$ & $p$ \\
\hline \multicolumn{5}{|l|}{ Baseline factors } \\
\hline Age (years) & $49 \pm 14$ & $53 \pm 10$ & $48 \pm 14$ & 0.26 \\
\hline Sex (men), $n(\%)$ & $23 / 40(58)$ & 8/9 (89) & $15 / 31(48)$ & $0.03 *$ \\
\hline APACHE II admission & $23 \pm 8$ & $25 \pm 8$ & $23 \pm 9$ & 0.55 \\
\hline SOFA admission & $11(5-13)$ & $11(9-11)$ & $10(4-13)$ & 0.85 \\
\hline $\mathrm{BMI}>30 \mathrm{~kg} / \mathrm{m}^{2}, n(\%)$ & $10 / 40(25)$ & $2 / 9(22)$ & $8 / 31(26)$ & 0.83 \\
\hline Pregnancy, $n(\%)$ & $3 / 40(8)$ & $0 / 9(0)$ & $3 / 31(10)$ & 0.33 \\
\hline Diabetes, $n(\%)$ & $4 / 40(10)$ & $1 / 9(11)$ & 4/31 (13) & 0.89 \\
\hline Chronic heart failure, $n(\%)$ & 4/40 (10) & $1 / 9(11)$ & 3/31 (10) & 0.90 \\
\hline Chronic intermittent hemodialysis, $n(\%)$ & $1 / 40(3)$ & $0 / 9(0)$ & $1 / 31(3)$ & 0.59 \\
\hline \multicolumn{5}{|l|}{ Known risk factors } \\
\hline All, $n(\%)$ & $9 / 40(23)$ & $5 / 9(55)$ & 4/31 (12) & $0.007 *$ \\
\hline Hemato, $n(\%)$ & $2 / 40(5)$ & $0 / 9(0)$ & $2 / 31(6)$ & \\
\hline Solid organ Tx, $n(\%)$ & $3 / 40(8)$ & $3 / 9(33)$ & $0 / 31(0)$ & \\
\hline COPD, $n(\%)$ & $2 / 40(5)$ & $1 / 9(11)$ & $1 / 31(3)$ & \\
\hline Other, $n(\%)$ & $2 / 40(5)$ & $1 / 9(11)$ & $1 / 31(3)$ & \\
\hline \multicolumn{5}{|l|}{ Studied risk factors } \\
\hline CS 7 days before ICU, $n(\%)^{\mathrm{a}}$ & $14 / 40(35)$ & 7/9 (78) & $7 / 31(23)$ & $0.002 *$ \\
\hline Cumulative dose CS 7 days before ICU (mg) & $0(0-543)$ & $800(360-2635)$ & $0(0-0)$ & $0.005 *$ \\
\hline \multicolumn{5}{|l|}{ Outcome } \\
\hline Mechanical ventilation, $n(\%)$ & $35 / 40(88)$ & $8 / 9(89)$ & 27/31 (87) & 0.89 \\
\hline Mechanical ventilation days & $13(5-21)$ & $20(11-55)$ & $13(5-18)$ & 0.10 \\
\hline $\mathrm{NO} / \mathrm{HFOV}, n(\%)$ & $21 / 40(53)$ & $5 / 9(56)$ & $16 / 31(52)$ & 0.83 \\
\hline $\mathrm{ECMO}, n(\%)$ & $11 / 40(28)$ & $4 / 9(44)$ & $7 / 31(23)$ & 0.20 \\
\hline ECMO days & $0(0-6)$ & $0(0-11)$ & $0(0-0)$ & 0.31 \\
\hline Vasopressors, $n(\%)$ & 29/40 (73) & 7/9 (78) & $22 / 31(71)$ & 0.69 \\
\hline Vasopressor days & $2(0-6)$ & $3(1-10)$ & $2(0-5)$ & 0.53 \\
\hline Renal replacement therapy, $n(\%)$ & $13 / 40(33)$ & $5 / 9(56)$ & $8 / 31(26)$ & 0.09 \\
\hline Renal replacement therapy days & $0(0-5)$ & $7(0-32)$ & $0(0-1)$ & 0.07 \\
\hline Ventilator-associated pneumonia, $n(\%)$ & $16 / 40(40)$ & $4 / 9(44)$ & $12 / 31(39)$ & 0.76 \\
\hline Bacteremia, $n(\%)$ & $12 / 40(30)$ & $6 / 9(67)$ & $6 / 31(19)$ & $0.006 *$ \\
\hline Alive at ICU discharge, $n(\%)$ & $28 / 40(70)$ & $6 / 9(67)$ & $22 / 31(71)$ & 0.80 \\
\hline Alive at hospital discharge, $n(\%)$ & $27 / 39(69)$ & $5 / 8(63)$ & $22 / 31(71)$ & 0.64 \\
\hline Length of ICU stay & $16(8-28)$ & $26(13-69)$ & $15(7-25)$ & $0.03 *$ \\
\hline Length of hospital stay & $24(13-41)$ & $58(26-65)$ & $23(12-36)$ & $0.02 *$ \\
\hline
\end{tabular}

All = the combination of known IPA risk factors: COPD, cirrhosis, hematological disease (hemato), solid organ transplant (Tx) recipient or any other illness necessitating immunosuppressive therapy (other)

$I P A$ invasive pulmonary aspergillosis, APACHE Acute Physiology and Chronic Evaluation Score, SOFA Sequential Organ Failure Assessment, $B M I$ body mass index, $C O P D$ chronic obstructive pulmonary disease, $C S$ corticosteroids, $N O / H F O V$ nitric oxide/highfrequency oscillation ventilation, ECMO extracorporeal membrane oxygenation, $I C U$ intensive care unit

$* p<0.05$

a $4 / 14$ patients received corticosteroids (CS) as outpatients prior to ICU admission, 5/14 received CS in hospital prior to ICU admission, and 5/14 received CS as outpatients and in hospital prior to ICU admission

\section{Corticosteroid use}

Significantly more IPA patients received CS before ICU admission than non-IPA patients [7/9 $(78 \%)$ versus $7 / 31$ $(23 \%), p=0.002]$. The two IPA patients who did not receive CS before ICU admission received CS during ICU stay before IPA diagnosis, the first one from day 0 (the day of ICU admission) onwards for septic shock and the other one from day 2 onwards for late ARDS. The dosage of CS intake was also significantly higher in the IPA group [cumulative equivalent hydrocortisone dose of $800(360-2,635)$ versus 0 $(0-0) \mathrm{mg}, p=0.005]$. Moreover, on multivariate analysis, including also sex and known risk factors for IPA, use of CS before ICU admission was independently associated with presence of IPA [OR 14.4 (2.0-101.6), $p=0.007$ ].

\section{Discussion}

This retrospective study showed that $23 \%$ of critically ill patients admitted to ICU with $\mathrm{H} 1 \mathrm{~N} 1$ viral infection developed invasive aspergillosis as early as 3 days after ICU admission, being 2 days after H1N1 diagnosis. Use of CS 7 days before ICU admission was an independent risk factor for this complication.

To the best of our knowledge, this study is the first one to report such a high incidence of proven and probable IPA in critically ill H1N1 patients. Five of the nine IPA patients had proven IPA, based on microscopic evidence of Aspergillus in endobronchial biopsy. Four IPA patients were diagnosed with probable IPA using the modified EORTC criteria for ICU patients as published previously 
Table 2 Overview of all individual cases of invasive pulmonary aspergillosis (IPA)

\begin{tabular}{|c|c|c|c|c|c|c|c|c|c|}
\hline Patient & $\begin{array}{l}\text { GM } \\
\text { BAL }\end{array}$ & $\begin{array}{l}\text { GM } \\
\text { blood }\end{array}$ & $\begin{array}{l}\text { Fungi } \\
\text { BAL }\end{array}$ & $\begin{array}{l}\text { Bronchoscopic } \\
\text { lesion }\end{array}$ & $\begin{array}{l}\text { Fungi } \\
\text { biopsy }\end{array}$ & Infiltrates & $\begin{array}{l}\text { EORTC } \\
\text { definition }\end{array}$ & $\begin{array}{l}\text { Day of first } \\
\text { indication of } \\
\text { IPA after ICU } \\
\text { admission }\end{array}$ & $\begin{array}{l}\text { Predisposing } \\
\text { condition }\end{array}$ \\
\hline 1 & Y & Y & $\mathrm{N}$ & Y & NA & Y & Probable $^{\mathrm{a}}$ & 3 & CS before IPA \\
\hline 2 & $\mathrm{Y}$ & $\mathrm{N}$ & Y & $\mathrm{N}$ & NA & Y & Probable $^{\mathrm{a}}$ & 5 & CS before IPA \\
\hline 3 & Y & Y & Y & $\mathrm{N}$ & $\mathrm{Y}$ & Y & Proven & -5 & Kidney transplant \\
\hline 4 & $\mathrm{Y}$ & $\mathrm{N}$ & $\mathrm{Y}$ & $\mathrm{N}$ & $\mathrm{N}$ & $\mathrm{Y}$ & Probable $^{\mathrm{a}}$ & 10 & COPD \\
\hline 5 & $\mathrm{Y}$ & $\mathrm{Y}$ & Y & $\mathrm{N}$ & $\mathrm{Y}$ & Y & Proven & 0 & Kidney transplant \\
\hline 6 & $\mathrm{Y}$ & $\mathrm{Y}$ & Y & Y & $\mathrm{Y}$ & Y & Proven & -3 & Lung transplant \\
\hline 7 & $\mathrm{Y}$ & $\mathrm{Y}$ & Y & Y & NA & Y & Probable $^{\mathrm{a}}$ & 0 & TTP \\
\hline 8 & $\mathrm{Y}$ & $\mathrm{Y}$ & Y & Y & $\mathrm{Y}$ & Y & Proven & 8 & CS before IPA \\
\hline $9^{b}$ & $\mathrm{Y}$ & $\mathrm{Y}$ & Y & Y & $\mathrm{Y}$ & Y & Proven & 5 & CS before IPA \\
\hline
\end{tabular}

Fungi BAL Aspergillus spp. cultured from BAL, Bronchoscopic lesion bronchoscopically visualized tracheal or bronchial white lesions, Fungi biopsy microscopic evidence of dichotomous branching hyphae with positive culture of Aspergillus spp. in biopsy specimen, CS before IPA corticosteroid use before onset of IPA. The first diagnostic indication for IPA could be a lower tract respiratory sample culture, a positive BAL or serum galactomannan or microscopic evidence for Aspergillus. The day of the first indication of IPA is expressed relative to day of ICU admission (day 0). Proven cases are irrespective of host factor or clinical features. Host factors were defined according to [20].

$Y$ yes, $N$ no, $N A$ not available, $G M$ galactomannan (Aspergillus antigen), $B A L$ bronchoalveolar lavage, $C O P D$ chronic obstructive pulmonary disease, TTP thrombotic thrombocytopenic purpura

${ }^{\mathrm{a}}$ Host factor present

b IPA case hospitalized and diagnosed in Antwerp University Hospital

Fig. 1 Temporal distribution of H1N1 and IPA cases. Bar graph showing on the $x$ axis each month of the study period (September 2009 to March 2011) and on the $y$ axis the total number of patients diagnosed with H1N1 (total bar) and the number of these H1N1 patients with IPA (black bar). IPA invasive pulmonary aspergillosis

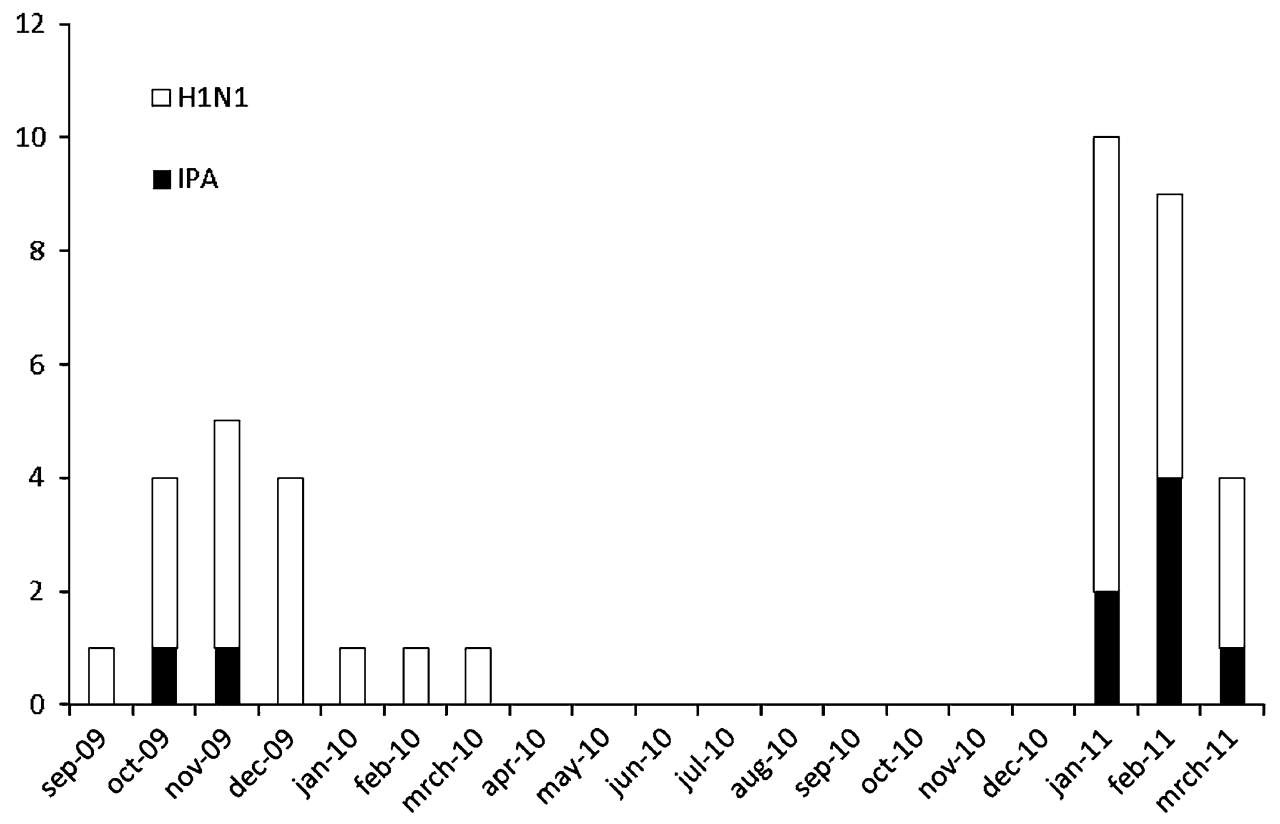

[20]. Increasing evidence indeed shows that ICU patients frequently develop IPA even without the classical risk factors according to the revised EORTC criteria [12, 20, 23-26]. This is an inherent limitation that applies to all reports on incidence of invasive aspergillosis in ICU patients. De Pauw et al. [19] also explicitly acknowledge this limitation in their paper on the revised EORTC definitions. The modified diagnosis of probable IPA in our ICU population should be further examined in multicentric studies. Finally, the key message of this paper is to draw the attention of the ICU physician to the fact that new risk categories for developing IPA (such as H1N1 with steroid use) may be identified, indicating the need for a high level of clinical vigilance to detect such extremely dangerous but treatable co-infection.

In a prospective study, Martin-Loeches et al. [10] reported fungal superinfections (IPA) in $1.8 \%$ of 220 CStreated critically ill H1N1 patients. Kim et al. [9] found 
similar results: $1.6 \%$ of 245 critically ill H1N1 patients were diagnosed with IPA. In comparison with these two studies, we noticed that our H1N1 patients were sicker and received more CS prior to ICU admission, which could explain the higher incidence of IPA in our study. Moreover, our diagnostic approach included not only BAL cultures, but also implementation of GM detection in serum and BAL. This latter test has been validated as a valuable diagnostic tool in a prospective study in our ICU [20]. Extensive environmental fungal sampling in the ICUs as well as in the hospital wards did not indicate an outbreak of IPA during the study period in both ICUs. A few years before the H1N1 flu seasons, Meersseman et al. [12] reported incidences of proven and probable IPA on the same ICU unit (UZL) where the current study was performed $[12,20]$. In a retrospective study between January 2000 and 2003, $5.7 \%(105 / 1,850)$ of ICU patients had proven or probable IPA [12]. In a prospective follow-up study between July 2005 and December 2006 , the same authors found $3 \%(34 / 1,109)$ of ICU patients to have proven or probable IPA [20]. Besides a high incidence of IPA and in line with others, we also found a worse outcome of IPA patients: ICU and hospital length of stay were significantly higher in IPA patients [27].

There are several reasons why critically ill patients with pneumonia due to H1N1 are at risk for developing aspergillosis. First, influenza viruses have been reported to cause cell-mediated destruction of airway epithelium and disruption of normal mucociliary clearance, fostering colonization and invasion with Aspergillus spp. [28-30]. Since 1952, 32 cases of Aspergillus superinfection associated with influenza have been reported [14, 15, 31]. A recent study of lung pathology in fatal $\mathrm{H} 1 \mathrm{~N} 1$ cases suggested that viral overload leads to altered immune responses, as with fatal $\mathrm{H} 5 \mathrm{~N} 1$ cases [32]. H1N1 leads to a necrotic pneumonia, as shown by increased lactate dehydrogenase (LDH) levels, being an ideal breeding medium for fungal colonization and growth of hyphae. Secondly, CS is frequently administered in conjunction with antiviral agents in order to limit inflammation in lung parenchyma. CS diminish host defenses and are increasingly recognized as a risk factor for developing aspergillosis in ICU patients [12, 23]. CS exert their immunosuppressive effects via transcriptional inhibition of nuclear factor-kappaB (NF- $\kappa \mathrm{B})$, leading to inhibition of cellular immunity [monocytes, T-lymphocytes, and polymorphonuclear leukocytes (PMNs)] which is essential for defense against IPA [23, 33]. Moreover, in vitro experiments showed enhanced growth of Aspergillus spp. on CS exposure. Finally, CS may also hinder the efficacy of antifungal therapy $[33,34]$. Administration of CS may be especially detrimental in severe influenza pneumonia, possibly by favoring persistent viral replication. This is also suggested by different recent clinical reports $[10,13$, 35, 36]. As in $\mathrm{H} 1 \mathrm{~N} 1$, Li et al. [37] reported that CS administration resulted in increased rates of secondary infections in severe acute respiratory syndrome (SARS) patients. However, the retrospective design of our study does not allow conclusions about causal relationships between H1N1, CS, and IPA. The limited number of patients in this study also limits the robustness of the multivariate analysis. In our study, early CS administration before ICU admission appeared to be relevant, since IPA was acquired early after ICU admission.

In conclusion, we found that a significant amount of critically ill patients with $\mathrm{H} 1 \mathrm{~N} 1$ virus infection developed IPA soon after admission to the ICU. Use of CS prior to ICU admission appeared to be one of the main risk factors. These findings may have consequences for daily clinical practice. The threshold to actively search for invasive aspergillosis in critically ill $\mathrm{H} 1 \mathrm{~N} 1$ patients (via BAL cultures and GM detection) should be low, and patients who are treated with CS warrant special attention. Moreover, one should be cautious about giving steroids to mechanically ventilated patients suffering from H1N1. These conclusions need further confirmation in larger studies.

\section{References}

1. Ramsey C, Kumar A (2011) H1N1: viral pneumonia as a cause of acute respiratory distress syndrome. Curr Opin Crit Care 17:64-71

2. Writing Committee of the WHO Consultation on Clinical Aspects of Pandemic (H1N1) 2009, Influenza Bautista E, Chotpitayasunondh T, Gao Z, Harper SA, Shaw M, Uyeki TM, Zaki SR, Hayden FG, Hui DS, Kettner JD, Kumar A, Lim M, Shindo N, Penn C, Nicholson KG (2010) Clinical aspects of pandemic 2009 influenza A (H1N1) virus infection. N Engl J Med 362:1708-1719
3. Peter JV, John P, Graham PL, Moran JL, George IA, Bersten A (2008) Corticosteroids in the prevention and treatment of acute respiratory distress syndrome (ARDS) in adults: metaanalysis. BMJ 336:1006-1009

4. Tang BM, Craig JC, Eslick GD, Seppelt I, McLean AS (2009) Use of corticosteroids in acute lung injury and acute respiratory distress syndrome: a systematic review and meta-analysis. Crit Care Med 37:1594-1603
5. Domínguez-Cherit G, Lapinsky SE, Macias AE, Pinto R, Espinosa-Perez L, de la Torre A, Poblano-Morales M, Baltazar-Torres JA, Bautista E, Martinez A, Martinez MA, Rivero E, Valdez R, Ruiz-Palacios G, Hernández M, Stewart TE, Fowler RA (2009) Critically Ill patients with 2009 influenza A (H1N1) in Mexico. JAMA 302:1880-1887 
6. Kumar A, Zarychanski R, Pinto R, Cook DJ, Marshall J, Lacroix J, Stelfox T, Bagshaw S, Choong K, Lamontagne F, Turgeon AF, Lapinsky S, Ahern SP, Smith O, Siddiqui F, Jouvet P, Khwaja $\mathrm{K}$, McIntyre L, Menon K, Hutchison J, Hornstein D, Joffe A, Lauzier F, Singh J, Karachi T, Wiebe K, Olafson K, Ramsey C, Sharma S, Dodek P, Meade M, Hall R, Fowler RA, Canadian Critical Care Trials Group H1N1 Collaborative (2009) Critically ill patients with 2009 influenza A (H1N1) infection in Canada. JAMA 302:1872-1879

7. ANZIC Influenza Investigators, Webb SA, Pettilä V, Seppelt I, Bellomo R, Bailey M, Cooper DJ, Cretikos M, Davies AR, Finfer S, Harrigan PW, Hart GK, Howe B, Iredell JR, McArthur C, Mitchell I, Morrison S, Nichol AD, Paterson DL, Peake S, Richards B, Stephens D, Turner A, Yung M (2009) Critical care services and 2009 H1N1 influenza in Australia and New Zealand. N Engl J Med 361:1925-1934

8. Brun-Buisson C, Richard JC, Mercat A, Thiebaut AC, Brochard L (2011) Early corticosteroids in severe influenza $\mathrm{A} / \mathrm{H} 1 \mathrm{~N} 1$ pneumonia and acute respiratory distress syndrome. Am J Respir Crit Care Med 183:1200-1206

9. Kim SH, Hong SB, Yun SC, Choi WI, Ahn JJ, Lee YJ, Lee HB, Lim CM, Koh Y, Korean Society of Critical Care Medicine H1N1 Collaborative (2011)

Corticosteroid treatment in critically ill patients with pandemic influenza A/H1N1 2009 infection: analytic strategy using propensity scores. Am J Respir Crit Care Med 183:1207-1214

10. Martin-Loeches I, Lisboa T, Rhodes A, Moreno RP, Silva E, Sprung C, Chiche JD, Barahona D, Villabon M, Balasini C, Pearse RM, Matos R, Rello J, ESICM H1N1 Registry Contributors (2011) Use of early corticosteroid therapy on ICU admission in patients affected by severe pandemic (H1N1) v influenza A infection. Intensive Care Med 37:272-283

11. Guinea J, Torres-Narbona M, Gijón P, Muñoz P, Pozo F, Peláez T, de Miguel J, Bouza E (2010) Pulmonary aspergillosis in patients with chronic obstructive pulmonary disease: incidence, risk factors, and outcome. Clin Microbiol Infect 16:870-877

12. Meersseman W, Vandecasteele SJ, Wilmer A, Verbeken E, Peetermans WE, Van Wijngaerden E (2004) Invasive aspergillosis in critically ill patients without malignancy. Am J Respir Crit Care Med 170:621-625

13. Lat A, Bhadelia N, Miko B, Furuya EY, Thompson GR 3rd (2010) Invasive aspergillosis after pandemic (H1N1) 2009. Emerg Infect Dis 16:971-973
14. Adalja AA, Sappington PL, Harris SP, Rimmele T, Kreit JW, Kellum JA, Boujoukos AJ (2011) Isolation of Aspergillus in three $2009 \mathrm{H} 1 \mathrm{~N} 1$ influenza patients. Influenza Other Respir Viruses 5:225-229

15. Garcia-Vidal C, Barba P, Arnan M, Moreno A, Ruiz-Camps I, Gudiol C, Ayats J, Ortí G, Carratalà J (2011) Invasive aspergillosis complicating pandemic influenza A (H1N1) infection in severely immunocompromised patients. Clin Infect Dis 53:e16-e19

16. Kim SH, Kim MN, Lee SO, Choi SH, Kim YS, Woo JH, Lim CM, Koh Y, Hong SB (2012) Fatal pandemic influenza $\mathrm{A} / \mathrm{H} 1 \mathrm{~N} 1$ infection complicated by probable invasive pulmonary aspergillosis. Mycoses 55:189-192

17. Passouant $\mathrm{O}$, Mateu P, Commandini M, Brenkle K, Just B (2011) Pulmonary aspergillosis in nonimmunocompromised patient with acute respiratory distress syndrome during A (H1N1) infection. Ann Fr Anesth Reanim 30:e75-e76

18. Vehreschild JJ, Bröckelmann PJ, Bangard C, Verheyen J, Vehreschild MJ, Michels G, Wisplinghoff $\mathrm{H}$, Cornely OA (2011) Pandemic 2009 influenza A (H1N1) virus infection coinciding with invasive pulmonary aspergillosis in neutropenic patients. Epidemiol Infect [Epub ahead]

19. De Pauw B, Walsh TJ, Donnelly JP, Stevens DA, Edwards JE, Calandra T, Pappas PG, Maertens J, Lortholary O, Kauffman CA, Denning DW, Patterson TF, Maschmeyer G, Bille J, Dismukes WE, Herbrecht R, Hope WW, Kibbler CC, Kullberg BJ, Marr KA, Muñoz P, Odds FC, Perfect JR, Restrepo A, Ruhnke M, Segal BH, Sobel JD, Sorrell TC, Viscoli C, Wingard JR, Zaoutis T, Bennett JE; European Organization for Research and Treatment of Cancer/ Invasive Fungal Infections Cooperative Group, National Institute of Allergy and Infectious Diseases Mycoses Study Group (EORTC/MSG) Consensus Group (2008) Revised definitions of invasive fungal disease from the European Organization for Research and Treatment of Cancer/Invasive Fungal Infections Cooperative Group and the National Institute of Allergy and Infectious Diseases Mycoses Study Group (EORTC/MSG) Consensus Group. Clin Infect Dis 46:1813-1821

20. Meersseman W, Lagrou K, Maertens J, Wilmer A, Hermans G, Vanderschueren S, Spriet I, Verbeken E, Van Wijngaerden E (2008) Galactomannan in bronchoalveolar lavage fluid: a tool for diagnosing aspergillosis in intensive care unit patients. Am J Respir Crit Care Med 177:27-34
21. Stynen D, Goris A, Sarfati J, Latge JP (1995) A new sensitive sandwich enzyme-linked immunosorbent assay to detect galactofuran in patients with invasive aspergillosis. J Clin Microbiol 33:497-500

22. Sehulster L, Chinn RY (2003) Guidelines for environmental infection control in health-care facilities. Recommendations of CDC and the Healthcare Infection Control Practices Advisory Committee (HICPAC). MMWR Recomm Rep 52:1-42

23. Vandewoude KH, Blot SI, Depuydt P, Benoit D, Temmerman W, Colardyn F, Vogelaers D (2006) Clinical relevance of Aspergillus isolation from respiratory tract samples in critically ill patients. Crit Care 10:R31

24. Bulpa PA, Dive AM, Garrino MG, Delos MA, Gonzalez MR, Evrard PA, Glupczynski Y, Installé EJ (2001) Chronic obstructive pulmonary disease patients with invasive pulmonary aspergillosis: benefits of intensive care? Intensive Care Med 27:59-67

25. Garnacho-Montero J, Amaya-Villar R, Ortiz-Leyba C, León C, Alvarez-Lerma $\mathrm{F}$, Nolla-Salas J, Iruretagoyena JR, Barcenilla F (2005) Isolation of Aspergillus spp. from the respiratory tract in critically ill patients: risk factors, clinical presentation and outcome. Crit Care 9:R191-R199

26. Meersseman W, Lagrou K, Maertens J, Van Wijngaerden E (2007) Invasive aspergillosis in the intensive care unit. Clin Infect Dis 45:205-216

27. Vandewoude KH, Blot SI, Benoit D, Colardyn F, Vogelaers D (2004) Invasive aspergillosis in critically ill patients: attributable mortality and excesses in length of ICU stay and ventilator dependence. J Hosp Infect 56:269-276

28. Clancy CJ, Nguyen MH (1998) Acute community-acquired pneumonia due to Aspergillus in presumably immunocompetent hosts: clues for recognition of a rare but fatal disease. Chest 114:629-634

29. Lewis DE, Gilbert BE, Knight V (1986) Influenza virus infection induces functional alterations in peripheral blood lymphocytes. J Immunol 137:3777-3781

30. Sedger LM, Hou S, Osvath SR, Glaccum MB, Peschon JJ, van Rooijen N, Hyland L (2002) Bone marrow B cell apoptosis during in vivo influenza virus infection requires TNF-alpha and lymphotoxin-alpha. J Immunol 169:6193-6201

31. Abbott JD, Fernando HV, Gurling K, Meade BW (1952) Pulmonary aspergillosis following post-influenzal bronchopneumonia treated with antibiotics. Br Med J 1:523-525 
32. Mauad T, Hajjar LA, Callegari GD, da Silva LF, Schout D, Galas FR, Alves VA, Malheiros DM, Auler JO Jr,

Ferreira AF, Borsato MR, Bezerra SM, Gutierrez PS, Caldini ET, Pasqualucci

CA, Dolhnikoff M, Saldiva PH (2010) Lung pathology in fatal novel human influenza A (H1N1) infection. Am J Respir Crit Care Med 181:72-79

33. Lionakis MS, Kontoyiannis DP (2003) Glucocorticoids and invasive fungal infections. Lancet 362:1828-1838
34. Ng TT, Robson GD, Denning DW (1994) Hydrocortisone-enhanced growth of Aspergillus spp.: implications for pathogenesis. Microbiology 140(9):2475-2479

35. Giannella M, Alonso M, Garcia de Viedma D, Lopez Roa P, Catalán P, Padilla B, Muñoz P, Bouza E (2011) Prolonged viral shedding in pandemic influenza A (H1N1): clinical significance and viral load analysis in hospitalized patients. Clin Microbiol Infect 17:1160-1165
36. Xi X, Xu Y, Jiang L, Li A, Duan J, Du B (2010) Hospitalized adult patients with 2009 influenza A (H1N1) in Beijing, China: risk factors for hospital mortality. BMC Infect Dis 10:256

37. Li XW, Jiang RM, Guo JZ (2003) Glucocorticoid in the treatment of severe acute respiratory syndrome patients: a preliminary report. Zhonghua Nei Ke Za Zhi 42:378-381 